\title{
The functional role of GABA and glycine in monaural and binaural processing in the inferior colliculus of horseshoe bats
}

\author{
Marianne Vater ${ }^{1,2}$, Hartmann Habbicht ${ }^{2}$, Manfred Kössl ${ }^{1}$ and Benedikt Grothe ${ }^{1}$ \\ 1 Zoologisches Institut der Universität München, Luisenstr. 14, W-8000 München 2, FRG \\ ${ }^{2}$ Institut für Zoologic der Universität Regensburg, Universitätsstr. 31, W-8400 Regensburg, FRG
}

Accepted June 29, 1992

Summary. The functional role of GABA and glycine in monaural and binaural signal analysis was studied in single unit recordings from the central nucleus of the inferior colliculus (IC) of horseshoe bats (Rhinolophus rouxi) employing microiontophoresis of the putative neurotransmitters and their antagonists bicuculline and strychnine.

Most neurons were inhibited by GABA $(98 \%$; $N=107)$ and glycine $(92 \% ; N=118)$. Both neurotransmitters appear involved in several functional contexts, but to different degrees.

Bicuculline-induced increases of discharge activity ( $99 \%$ of cells; $N=191$ ) were accompanied by changes of temporal response patterns in $35 \%$ of neurons distributed throughout the IC. Strychnine enhanced activity in only $53 \%$ of neurons $(N=147)$; cells exhibiting response pattern changes were rare $(9 \%)$ and confined to greater recording depths. In individual cells, the effects of both antagonists could markedly differ, suggesting a differential supply by GABAergic and glycinergic networks.

Bicuculline changed the shape of the excitatory tuning curve by antagonizing lateral inhibition at neighboring frequencies and/or inhibition at high stimulation levels. Such effects were rarely observed with strychnine.

Binaural response properties of single units were influenced either by antagonization of inhibition mediated by ipsilateral stimulation (bicuculline) or by changing the strength of the main excitatory input (bicuculline and strychnine).

Key words: Audition - Microiontophoresis - Single units - Bicuculline - Strychnine

Abbreviations: $B F$ best frequency; $B i c$ bicuculline; $C$ control; $C F$ constant frequency; $C N$ cochlear nucleus; $D N L L$ dorsal nucleus of the lateral lemniscus; $F M$ frequency modulation; $G A B A$ gamma amino butyric acid; $I C$ inferior colliculus; $L S O$ lateral superior olive; Str strychnine

Correspondence to: Marianne Vater, Institut für Zoologie der Universität Regensburg

\section{Introduction}

The inferior colliculus (IC) holds a keyposition in the ascending auditory pathway. It is the target site of multiple ascending pathways from the lower brain stem, which carry monaural as well as binaural information and terminate in either segregated or overlapping fashion in the central nucleus (reviews: Irvine 1986; Oliver and Shneiderman 1991). Many aspects of auditory processing at the midbrain level crucially depend on an interplay of excitation and inhibition. In monaural signal analysis, inhibition is involved in shaping temporal response patterns of single units and the form of the excitatory tuning curve in particular at high levels of stimulation, in creating nonmonotonic spike count functions and in producing selectivity for particular frequency-time structures of complex acoustic stimuli (review: Aitkin 1986; Suga 1969; Suga and Schlegel 1973). In binaural signal analysis, excitatory responses evoked by stimulation of one ear are counteracted by inhibition derived from stimulation of the other ear thus producing sensitivity for interaural level or interaural time differences (review: Caird 1991). Recent neuropharmacological and immunocytochemical studies have shown that inhibitory interactions within the auditory system are very likely based on neuronal networks using gamma-aminobutyric acid (GABA) or glycine as transmitters. Each brainstem auditory nucleus contains a typical profile of neurons immunoreactive for either GABA or glycine. These putatively inhibitory cells may encompass local interneurons, as well as projection neurons (GABA: e.g. Moore and Moore 1987; Glycine: review: Wenthold and Hunter 1990). For some ascending pathways, which converge onto the auditory midbrain, a predominantly inhibitory role has been proposed. These include the pathway arising in the dorsal nucleus of the lateral lemniscus (DNLL), where each projection cell is GABA-immunoreactive (Adams and Mugnaini 1984; Shneiderman et al. 1988), and a pathway arising from glycine-immunoreactive cells in the ventral nucleus of the lateral lemniscus (Vater et al. 1992a). In other ascending tracts such as derived from the lateral 
superior olive (LSO; Saint Marie et al. 1989), excitatory and inhibitory projections are mixed. Neuropharmacological experiments on single IC-neurons have shown that GABA and glycine are potent agents to inhibit the neuronal responses (Faingold et al. 1989, 1991). Microiontophoretic application of the GABA-antagonist bicuculline showed that phasic on-responses of single units were changed to tonic by blocking the inhibition caused by intrinsic GABA. Additionally, bicuculline influenced rate-level functions and modified binaural response properties of single IC-neurons (Faingold et al. $1989,1991)$. Glycine is known to shape the output of cells in the cochlear nucleus (CN) and to mediate binaural inhibition in the LSO (review: Caspary 1990), but its role in information processing at the midbrain level has not yet been fully elucidated. Application of the glycine antagonist strychnine can enhance discharge activity of single IC-neurons (Faingold et al 1991).

The auditory system of horseshoe bats is exquisitely sharply tuned to a narrow frequency band close to the constant frequency (CF) component of its echolocation signal at about $78 \mathrm{kHz}$ (review: Neuweiler 1990). Due to an expanded representation within the cochlea, these frequencies are vastly overrepresented at all stations of the ascending auditory pathway. The mechanism of enhancing tuning capacities beyond those normally measured in other mammals or at other frequencies in the horseshoe bat's audiogram resides in specialized hydromechanical properties of the cochlear duct (e.g. Vater et al. 1985).

The IC of bats has been studied extensively in neurophysiological and neuroanatomical research (review: Pollak and Casseday 1989). Single unit recordings in the IC have shown that the excitatory tuning curves are flanked by lateral inhibitory sidebands (Möller 1978; Suga 1969; Suga and Schlegel 1973), which can even close the normally V-shaped excitatory area at high stimulus levels (Vater et al. 1979; Rübsamen et al. 1988; Schmidt et al. 1991). The exact arrangement of inhibitory fields governs the neuronal selectivity for pure tones, frequency-modulations (FM) or noise (Suga and Schlegel 1973). Binaural stimulation has revealed a variety of different response types with a predominance of cells excited by the contralateral ear and inhibited by the ipsilateral ear (Schlegel 1977a; Wenstrup et al. 1986).

Immunocytochemical data on the distribution pattern of putatively inhibitory transmitters in the auditory system of horseshoe bats (Vater et al. 1990a) have shown that the IC contains a subpopulation of GABAimmunoreactive cells as well as puncta (interpreted as axonal end structures) and glycine immunoreactive puncta. Whereas GABA-immunoreactive puncta can be derived from intrinsic as well as extrinsic sources, glycine immunoreactive puncta appear to be derived from ascending glycinergic projections from the lower brainstem. Interestingly the puncta labeling pattern obtained with antisera to the respective transmitters are not fully in congruence: in middle portions of the central nucleus (ICc), the distributions are partially overlapping whereas in lateral and ventrolateral parts of the ICc, they are clearly segregated. This suggests that some IC-neurons might receive convergent input from GABAergic and glycinergic systems, whereas others are predominantly influenced by one of these inhibitory inputs. Since the functional significance of convergence or segregation of multiple excitatory and inhibitory inputs at the level of the IC is still unclear, it is important to determine, to what degree the response features of IC-neurons depend on convergence of different inputs or reflect information already preprocessed in the lower brainstem. Microiontophoresis of putative neurotransmitters and their antagonists represents a powerful tool to address this question.

The present study investigates the functional role of GABA and glycine in shaping monaural and binaural response properties of single neurons of the ICc in the horseshoe bat by employing the technique of microiontophoresis of these neurotransmitters and their antagonists bicuculline and strychnine. We were particularly interested in the questions if and to what extent GABAergic and glycinergic mechanisms within the IC are shaping temporal response patterns, tuning characteristics and rate/ level functions. Parts of this study have been presented in abstract form (Vater et al. 1990b).

\section{Material and methods}

The techniques for recording single unit activity in the IC of awake horseshoe bats have been described in earlier reports (e.g. Pollak and Schuller 1981). In this study we used 5 horseshoe bats (Rhinolophus rouxi obtained in Sri Lanka). Under deep halothane anaesthesia, a small metal bolt, serving to fix the head in the stereotactic device was chronically glued to the exposed skull surface with dental cement. A small hole was drilled into the bone overlying the IC and the dura mater was opened. A silver wire serving as the indifferent electrode was chronically implanted in the cerebellum. The bats were allowed to recover from anaesthesia after the wound surfaces had been treated with local anaesthetic (lidocaine) and the opening in the skull was closed with bone wax.

During recording, which started earliest $24 \mathrm{~h}$ after surgery, the bats were awake with woundsurfaces continuously treated with local anaesthetic. They were restrained in a cushioned body holder and fixed reproducibly in the stereotactic device. Temperature of the sound attenuated room was kept at $30-32{ }^{\circ} \mathrm{C}$. Extracellular action potentials were recorded with finetipped glass microelectrodes filled with 1.5 or $3 \mathrm{M} \mathrm{KCl}$ (impedance 4-12 M 2 ) glued to the fivebarreled injection pipette (Havey and Caspary 1980). Collective tip diameter of the latter was $8-12 \mu \mathrm{m}$ and the recording electrode protruded between $8-20 \mu \mathrm{m}$. The barrels were filled with the following drugs: GABA (0.5 $M$; pH 3.5), bicuculline methiodide (GABA-A-receptor antagonist; Sigma; $0.005 M ; \mathrm{pH} 3.0)$ glycine $(0.5 M ; \mathrm{pH} 4.0)$ and strychnine $\mathrm{HCl}$ (Sigma; $0.01 M ; \mathrm{pH} \mathrm{3.5)}$. One barrel was filled with $1 M$ sodium-acetate (pH 7.2) and served as balancing channel. The drugs were administered by positive currents (List Neurophore) ranging from $2 \mathrm{nA}$ to maximally $100 \mathrm{nA}$ and a negative holding current of $15 \mathrm{nA}$ was used in between applications to avoid leakage. To test for specificity of effects, the agonist and the antagonist were simultaneously administered. In all cells tested, bicuculline and strychnine only blocked the inhibitory effect of the corresponding agonist. Current injections via the balance channel did not alter the neuronal responses. Pure tone bursts were either delivered freefield to the contralateral ear by a custom made condensor loudspeaker situated at $12 \mathrm{~cm}$ distance at optimal azimuth angle or binaurally under closed field conditions via specially designed earphones (Schlegel 1977b). Tone pulses were $50 \mathrm{~ms}$ long with rise-fall times of $2 \mathrm{~ms}$ and delivered at repetition rates of $4-8 \mathrm{~Hz}$. 
After isolation of a single unit, the best frequency (BF), i.e. the frequency of lowest threshold and the tuning curve were determined by audiovisual criteria. The temporal response patterns at different frequency-level combinations of the stimulus before, during and after drug application were recorded on-line with a PDP-11 or a PC over 60 presentations of an identical stimulus. Stimulus or drug application parameters were only changed until full recovery from previous drug administrations was achieved. The data were analysed in either dot-displays or as post-stimulus-time (PST-) histograms (Programs M. Betz; M. Baumann). For quantitative analysis, the spikes were counted in a time window corresponding to stimulus duration, but corrected for response latency. Electrode position was systematically varied under stereotactic coordinates. At the last recording day, small iontophoretic injections of horseradish peroxidase (HRP) were made through the recording pipette in 3 bats. Following a survival time of $12-24 \mathrm{~h}$, the bats received a lethal dosis of nembutal and were perfused through the heart with fixative adaequate for following HRP-histochemistry (for details see Feng and Vater 1985).

\section{Results}

Iontophoretic application of GABA inhibited tone evoked and spontaneous activity in $98 \%$ of cells tested $(N=107)$. With application currents of $40-50 \mathrm{nA}$, an average reduction of tone evoked discharge rate to $27 \%$ of the control values was obtained (range $0.8 \%$ to $52.6 \%$ ). Glycine had an inhibitory effect in $92 \%$ of the sample $(N=118)$. Average reduction of the tone evoked discharge rates obtained at application currents of 40-50 nA amounted to $37 \%$ of control values (range $2 \%$ to $87 \%$ ).

Bicuculline effectively antagonized the effect of simultaneously applied GABA and when administered alone, it produced changes in the response characteristics in $99 \%$ of single units $(N=191)$. These included increases in tone evoked and spontaneous discharge activity, which could be accompanied by alterations of the temporal discharge patterns and the frequency response charac- teristics. With application currents of 50 to $60 \mathrm{nA}$, the tone evoked discharge rate was increased on the average to $353 \%$ of the control values (range $112 \%$ to $1550 \%$ ). In cells, which under control conditions were unresponsive to pure tones, a maximum increase in tone evoked discharge activity by a factor of 294 was found. Strychnine antagonized the effect of simultaneously applied glycine and, when administered alone could produce similar effects as bicuculline, but in a much more restricted population of cells. It increased the neuronal discharge activity in only $53 \%$ of the sample $(N=147)$. A large proportion of cells ( $46.3 \%$ of the sample) was unaffected by strychnine according to the criterion that discharge rate stayed within $\pm 10 \%$ of the control value. The response of one neuron was reduced to $44 \%$ of the control value. On the average, tone evoked discharge rate was increased to $196 \%$ of control values (range $115 \%$ to $491 \%$; application currents 50-60 nA). A maximum increase by a factor of 18 was observed at application currents of $80 \mathrm{nA}$.

Out of 104 cells tested with both bicuculline and strychnine, $55.8 \%$ were only sensitive for bicuculline and $44.2 \%$ of cells were sensitive to both drugs.

\section{General aspects of drug action}

The effects of all agents were dose dependent as illustrated in Fig. 1 for GABA and bicuculline, respectively.

With increasing application currents (dosage), GABA progressively reduced the tonic component of the neuronal response, thus modifying the discharge pattern to a phasic-on response prior to completely suppressing the activity. The effect of bicuculline is illustrated for a neuron, which under control conditions produced a strong phasic-on response followed by a weak tonic component.

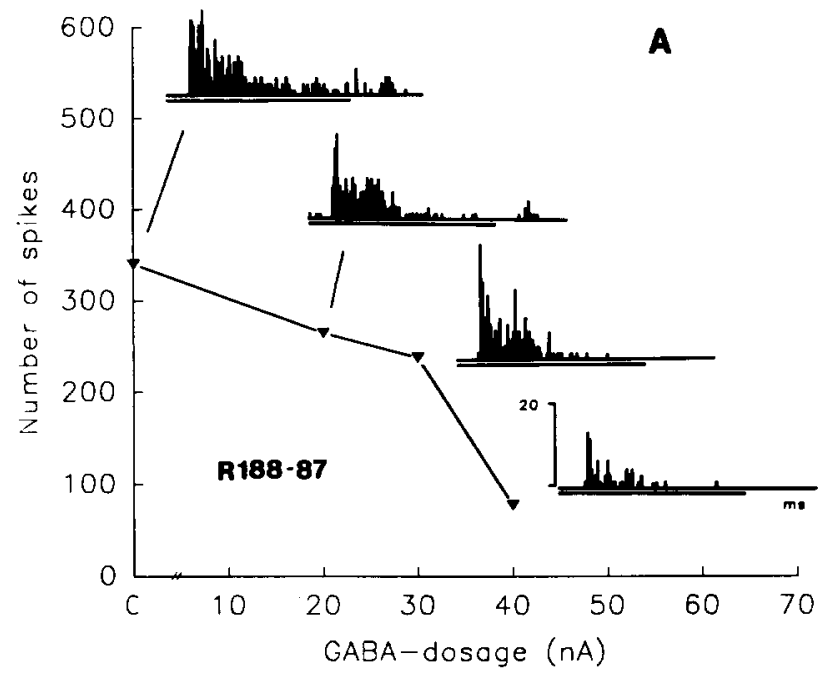

Fig. 1. Dose dependent effects of GABA (A) 2 and the GABA-Areceptor antagonist bicuculline $(B i c ; B)$ on the response patterns of two single IC-neurons. The number of spikes per 60 presentations of the pure tone pulse is plotted vs. the injection current. The control condition corresponds to $-15 \mathrm{nA}$ (holding current). The neurons' response patterns are shown as PST-histograms (60 stimu-

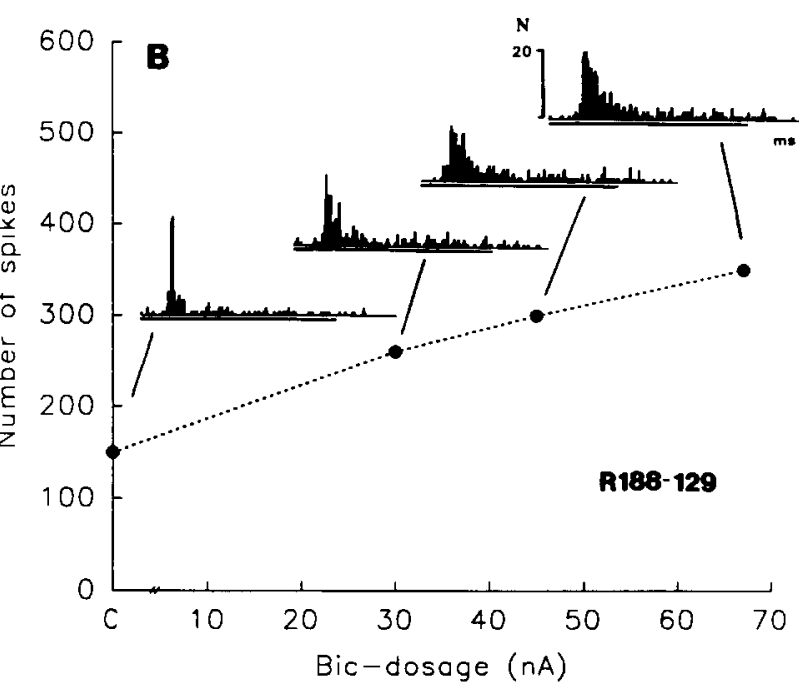

lus presentations; bin width $0.3 \mathrm{~ms}$ ) at the corrresponding injection currents. Duration of the tone pulse $(50 \mathrm{~ms})$ is indicated by bars below the abscissa (full scale value: $120 \mathrm{~ms}$ ). Stimulus frequency is $69.8 \mathrm{kHz}(\mathrm{R} 188-87)$ and $71.2 \mathrm{kHz}(\mathrm{R} 288-129)$, stimulus level is $40 \mathrm{~dB}$ SPL in both neurons 
"Level-change"

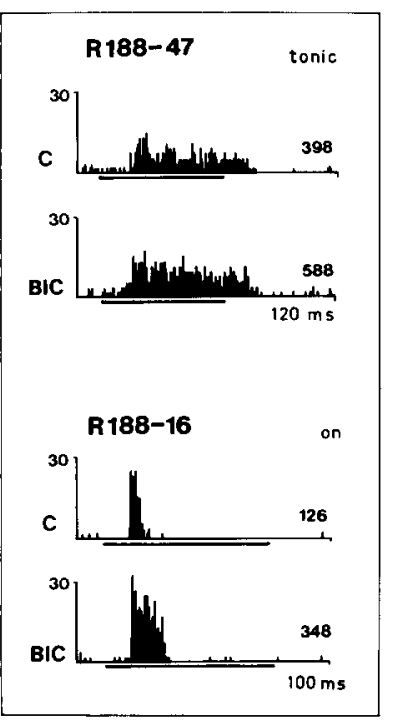

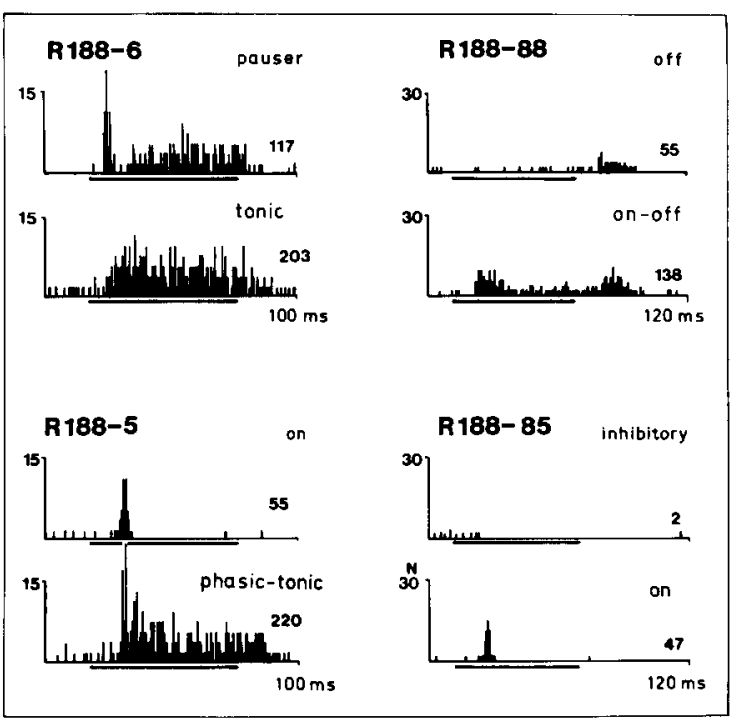

Fig. 2. Examples of the effects of bicuculline on the temporal response patterns of single IC-neurons. The top histogram for each neuron represents the response under control $(C)$ conditions and the bottom histogram under bicuculline $(B I C)$ application; numbers give total number of tone evoked spikes. The left pannel shows a tonic cell (R188-47; stimulus at $78.7 \mathrm{kHz}$ and $60 \mathrm{~dB}$ SPL for both conditions; application current $50 \mathrm{nA})$ and a phasic cell (R188-16; $53.3 \mathrm{kHz}$; $20 \mathrm{~dB}$ SPL; application current $70 \mathrm{nA}$ ), which increased their discharge level under bicuculline application without changing the general type of response characteristics. The right pannel shows neurons changing discharge rate as well as the general structure of their response patterns under bicuculline application. Stimulus parameters and application currents: $73.2 \mathrm{kHz}$ at $5 \mathrm{~dB}$ SPL; $60 \mathrm{nA}$ (R188-6); $75.1 \mathrm{kHz}$ at $40 \mathrm{~dB}$ SPL; $50 \mathrm{nA}$ (R188-88); $31.8 \mathrm{kHz}$ at $50 \mathrm{~dB}$ SPL; $70 \mathrm{nA}(\mathrm{R} 188-5)$ and $50.4 \mathrm{kHz}$ at $40 \mathrm{~dB}$ SPL; $50 \mathrm{nA}$ (R188-85)
With increasing application currents, the phasic-on discharge activity was prolonged and the tonic discharge activity increased.

The action of GABA and glycine was characterized by fast onset and decay times in the range of seconds. We noted that in some cells, the onset of glycine effects could be slower than that of GABA, but we did not systematically investigate this parameter. The lowest application currents sufficient to produce inhibition ranged from 3 to $5 \mathrm{nA}$ for both putative neurotransmitters. The action of both antagonists was characterized by a slower time course of several minutes. Recovery times could be especially long after strychnine application (up to $15 \mathrm{~min}$ ). The lowest effective application currents for both antagonists ranged from 20 to $30 \mathrm{nA}$.

\section{Temporal response patterns}

In order to investigate, if intrinsic inhibitory circuits within the IC are involved in shaping temporal discharge patterns of single units, the neuronal responses prior to and during microiotontophoresis of bicuculline and strychnine were compared. The classification of temporal discharge patterns of single IC-neurons in response to pure tone bursts follows that given in previous studies (Möller 1978; Neuweiler and Vater 1977).

Figure 2 shows the temporal response patterns to pure tone stimuli of different IC-neurons under control conditions (top traces) and during microiontophoresis of bicuculline (lower traces). Basically two types of response changes were seen under the influence of the GABAantagonist. The first type comprises cells with sustained and phasic response patterns, where bicuculline increased the number of spikes per stimulus without affect- ing the basic response type ("level change"; Fig. 2 left pannel). The second type includes cells which in addition to increases in discharge level changed their temporal discharge patterns ("pattern change", Fig. 2 right pannel). Unit R188-6 responded with a pauser pattern under control conditions. Application of bicuculline abolished the gap in the response pattern and transformed the response to a tonic activity throughout stimulus duration. Most notably, the tight synchronization of discharges to stimulus onset was lost. The phasic-on neuron (unit R188-5) responded with vigorous phasic-tonic discharge activity under bicuculline application. The response of the phasic-off cell (unit R188-88) was altered to a sustained response with distinct discharge peaks to tone onset and offset. The inhibitory response pattern of unit R188-85 was changed to a phasic-on response under application of bicuculline.

Out of a total sample of 191 cells, $64 \%$ increased their discharge level during bicuculline-application, while 35\% additionally changed their response pattern. The proportions of sustained and phasic neurons belonging to these particular categories are summarized in Fig. 3 together with those cells, which under control conditions were unresponsive to pure tone stimuli ("non-PT" cells). The highest percentages of units that changed their response pattern under the influence of bicuculline were found among phasic responders (38\%) and non-PT-units $(100 \%)$.

Application of strychnine had similar effects in modifying temporal discharge activity, however the relative proportions of cells which exhibited pattern changes were much lower than with bicuculline (Fig. 3). For example only $7.2 \%$ of phasic cells and only $40 \%$ of nonPT cells changed their discharge pattern under the influence of the glycine antagonist. Furthermore, a high 


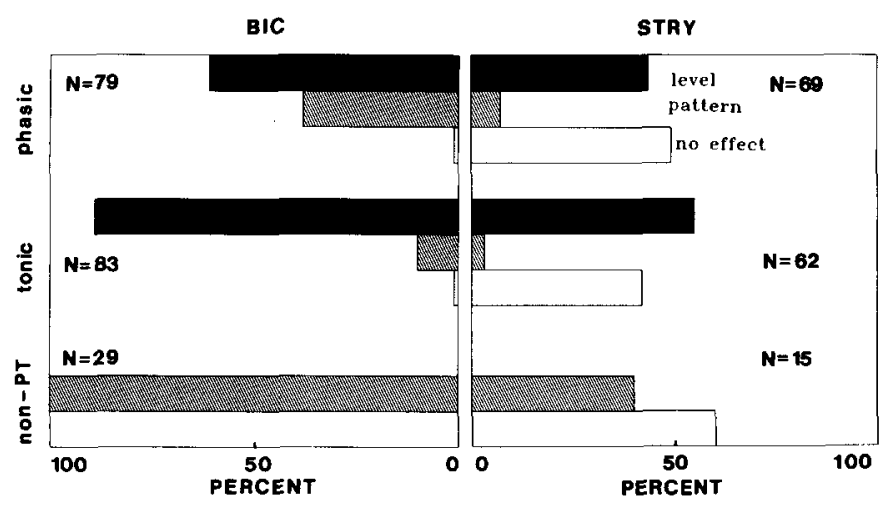

Fig. 3. Bar histograms showing the percentage of neurons, which exhibited a particular type of change in their response activity to the application of bicuculline (left pannel) and strychnine (right pannel). Black bars: Changes in discharge level without changing gross discharge pattern; hatched bars: changes of discharge level as well as gross response pattern; empty bars: no effect. The neurons are classified into phasic responders (top pannel); tonic responders (middle pannel) and cells, which could not be consistently excited with pure tone stimulation (non-PT, lower pannel). The relative percentage of neurons changing their discharge pattern is highest among phasic responders and those cells which could not be driven by pure tones. In the sample obtained with strychnine, there is a high percentage of unaffected cells in all three response pattern categories. The pure tone stimulus was set at best frequency between 20 to $40 \mathrm{~dB}$ above minimum threshold

percentage ( $46.3 \%$ out of 147 cells) of single units was unaffected by application of strychnine.

In individual cells, the effects of bicuculline and strychnine could be markedly different (Fig. 4). Unit R188-5 changed from a phasic-on response to a tonic pattern under bicuculline while being unaffected by strychnine. The off-response of unit R390-156 was transformed to an on-off pattern by bicuculline, whereas strychnine only slightly increased the off-response. The response of the highly spontaneous cell R288-111 reveals a phasic-on inhibitory component, which was removed by strychnine, but unaffected by bicuculline although it increased tone evoked discharge activity. In unit R390-127, both antagonists considerably increased discharge activity.

The differential effects of bicuculline and strychnine are most readily seen in cells which show a pattern change upon bicuculline application. $61 \%$ of these cells (total $N=31$ ) were unaffected by strychnine application; $19 \%$ increased the discharge rate with strychnine without changing the response pattern and $20 \%$ also revealed a pattern change with strychnine.

The spatial distribution of IC-neurons that were tested with microiontophoretic application of bicuculline and strychnine is shown in Fig. 5. Recordings are restricted to middle regions of the central nucleus of the IC and the sample is clearly biased in favour of dorsal and intermediate locations. In the sample obtained with bicuculline application, neurons changing their response pattern are found throughout the recording area with no preferential localization within particular depths or isofrequency laminae. In the sample obtained with strychnine, the different categories of neurons are partially
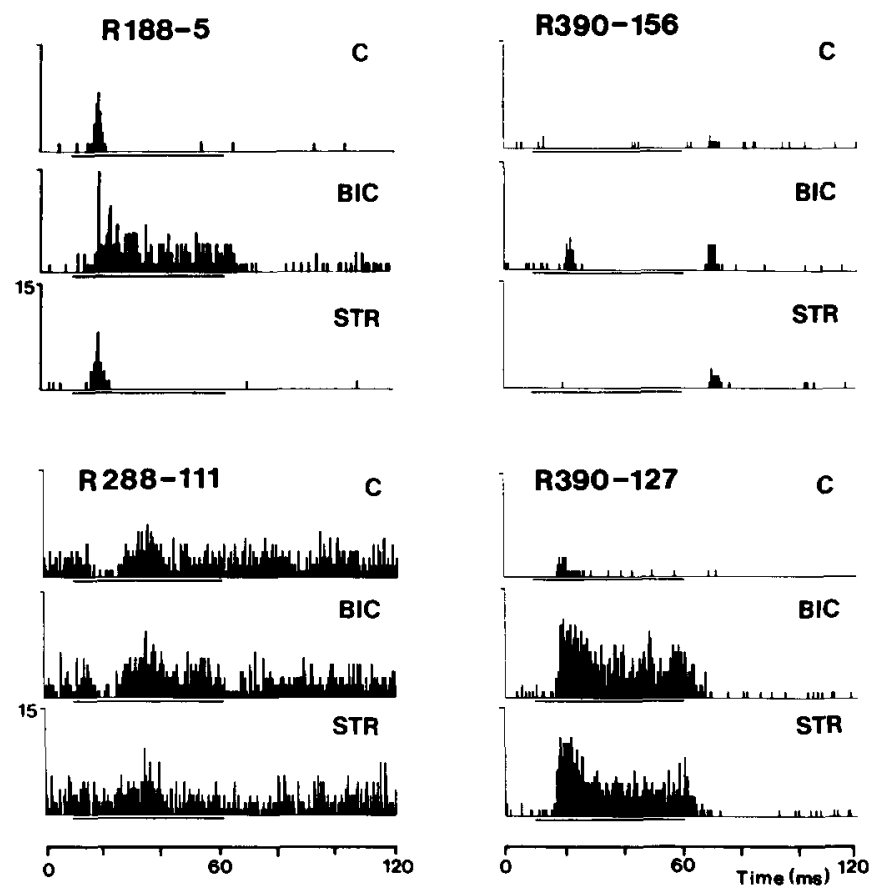

Fig. 4. Comparison of the effects of bicuculline $(B I C)$ and strychnine $(S T R)$ on the response patterns in different IC-units. Application currents for bicuculline and strychnine $70 \mathrm{nA}$. Stimulus parameters: $31.8 \mathrm{kHz}$ at $50 \mathrm{~dB}$ SPL (R188-5); $65.9 \mathrm{kHz}$ at $30 \mathrm{~dB}$ SPL (R390-156); $78.1 \mathrm{kHz}$ at $40 \mathrm{~dB}$ SPL (R288-111) and $68.9 \mathrm{kHz}$ at $30 \mathrm{~dB}$ SPL (R390-127)

segregated. Neurons with pattern change are restricted to recording depths larger than $900-1000 \mu \mathrm{m}$, neurons that changed their discharge level are found in depths of 400-500 $\mu \mathrm{m}$, intermingled with unaffected cells and preferentially at depths below $1000 \mu \mathrm{m}$.

\section{Spike count functions and frequency response characteristic}

Many IC-neurons possess inhibitory sidebands flanking the excitatory response area and the spike count functions of these cells are often distinctly non-monotonic due to inhibition at high stimulus levels (Möller et al. 1978; Schlegel 1977a).

The effect of bicuculline-application was tested in 12 cells, whose non-monotonic spike count functions possessed distinct upper thresholds at high stimulus levels. Bicuculline effectively increased the dynamic range in 10 of these neurons either by shifting the upper threshold (Fig. 6, unit R188-6) or by completely opening the response range towards high stimulus levels (Fig. 6, unit R188-101). In two cells with upper thresholds and 3 other nonmonotonic cells (e.g. Fig. 6 unit R188-87), bicuculline only increased the response level, but the general form of the spike count function was not altered. Strychnine was ineffective in 8 upper threshold neurons tested, but, like bicuculline, abolished the upper thresholds in one cell. 
BIC
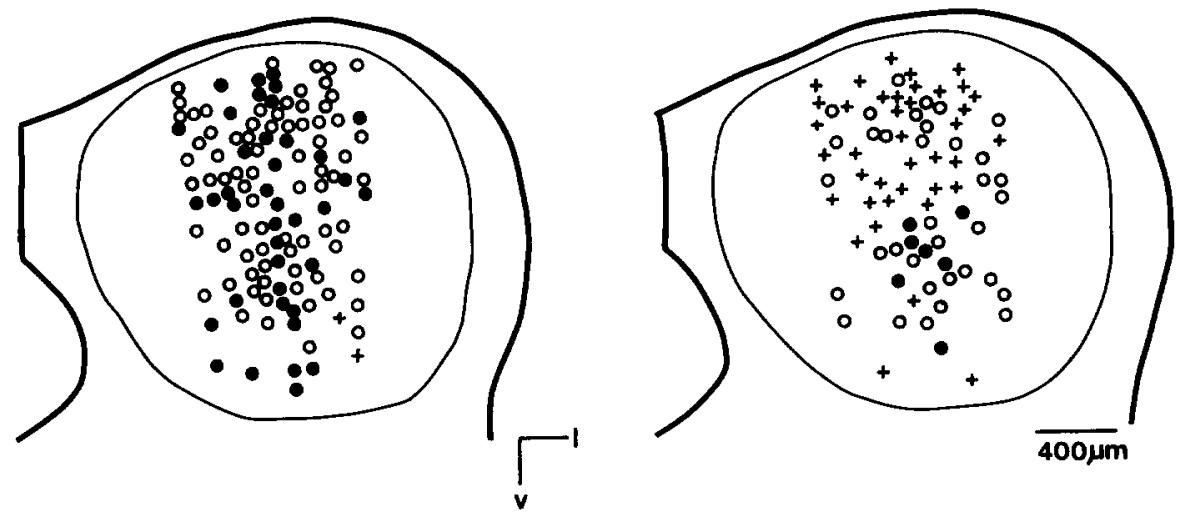

Fig. 5. Schematic representation of recording sites of single units in the $\mathrm{ICc}$ (frontal sections) tested with bicuculline (left) and strychnine (right). Open circles symbolize cells which increased the discharge level, filled circles indicate cells which increased the discharge levels and changed their response pattern; crosses denote cells which were unaffected. The electrode passes were reconstructed from stereotactic data using focal injections of HRP as reference points

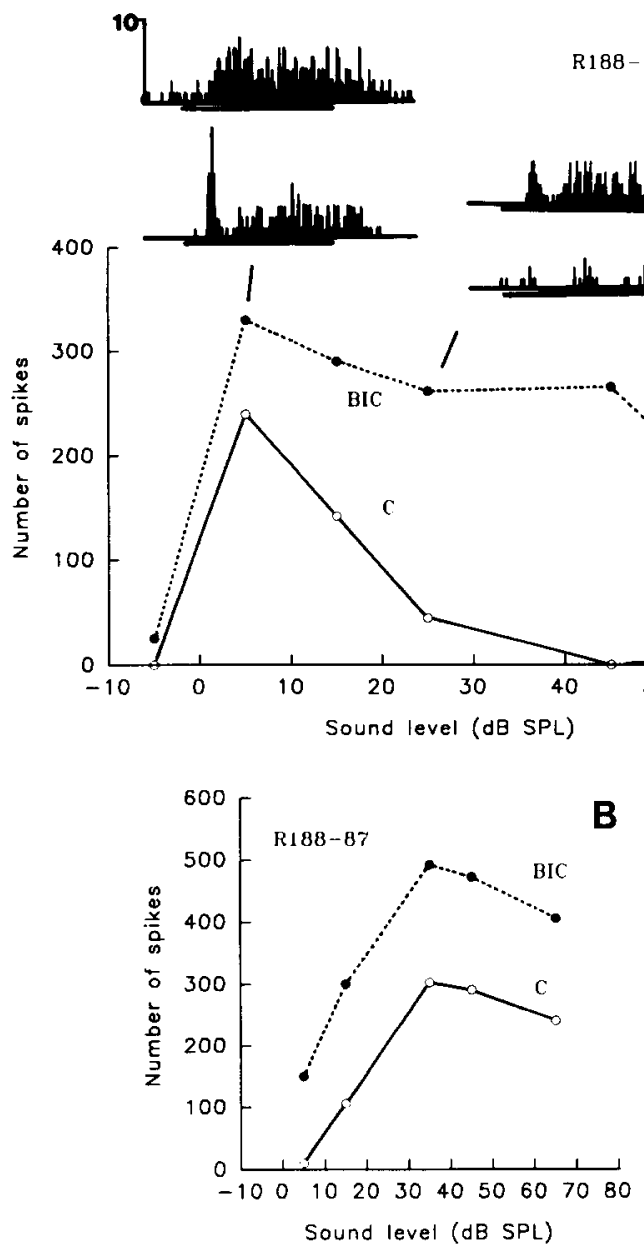

In addition, bicuculline strongly influenced the width and shape of the excitatory tuning curve. Figure 7A-C shows examples of single neurons with closed excitatory tuning curves under control conditions (open circles, solid lines). Application of bicuculline led to an expansion of the excitatory area indicated by closed circles and dotted lines. The closed tuning curves were either transformed into normal V-shaped tuning curves with or without distinct low frequency tails (Fig. 7A, B) or the response area was widened towards higher stimulus levels (Fig. 7C). These changes could be accompanied by a widening of the bandwidth measured $10 \mathrm{~dB}$ above minimal threshold (Fig. 7A) or this bandwidth was not significantly altered (Fig. 7C).

Changes in the bandwidth of the excitatory response area under bicuculline application were also observed in cells with normal $\mathrm{V}$-shaped tuning curves and BFs distributed throughout the bat's hearing range. Only three out of 19 cells did not widen the $10 \mathrm{~dB}$ bandwidth under bicuculline and all cells $(N=14)$ increased the $40 \mathrm{~dB}$ 

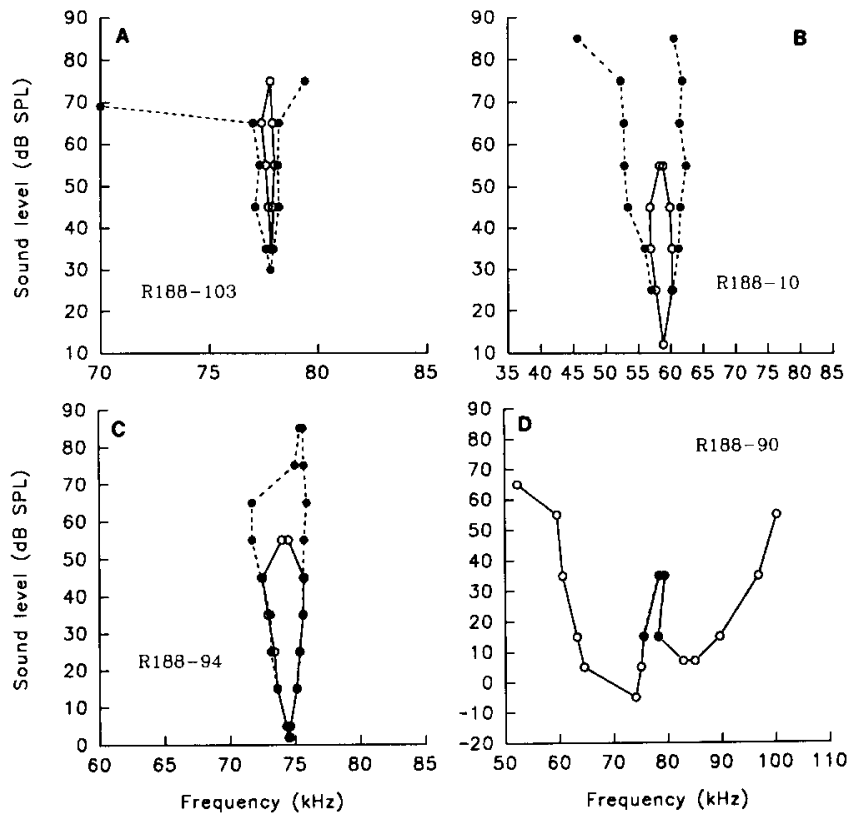

Fig. 7A-D. Tuning curves of different IC-neurons obtained under control conditions (open circles and continuous lines) and during bicuculline application (filled circels and dotted lines). Application currents for A-D: $50 \mathrm{nA}$ bandwidth. On the average, the $10 \mathrm{~dB}$ bandwidth was widened by a factor of 1.8 (SD 1.09) and the $40 \mathrm{~dB}$ bandwidth was increased by a factor of 2.4 (SD 1.46). In all of these neurons, the frequency of lowest threshold (BF) remained constant, but in 4 cells, the threshold at $\mathrm{BF}$ was lowered by 5 up to $37 \mathrm{~dB}$ SPL. In cells sharply tuned to the CF-component, a maximal increase in the $10 \mathrm{~dB}$ bandwidth from $200 \mathrm{~Hz}$ to $1.1 \mathrm{kHz}$ was obtained under bicuculline application. Expressed as $\mathrm{Q}_{10 \mathrm{~dB}}$ value (i.e. the $\mathrm{BF}$ divided by the $10 \mathrm{~dB}$ bandwidth), the filter quality decreased from a value of 330 under control conditions to a value of 70 under bicuculline application. In 10 cells, lateral inhibitory sidebands were evidenced by suppression of spontaneous discharge activity. In 5 of these cells, bicuculline application replaced the inhibitory response pattern by excitatory responses, while in the other cells, it only produced increases in spontaneous activity without antagonizing the inhibition.

The specialized shape of the tuning curve of some IC-cells is clearly not the result of inhibition within the IC. The neuron shown in Fig. 7D is an example of a rarely encountered cell type with double peaked excitatory fields. In these cells $(N=3)$, bicuculline did not change the shape of the response areas, in particular the gap separating the two excitatory fields could not be abolished.
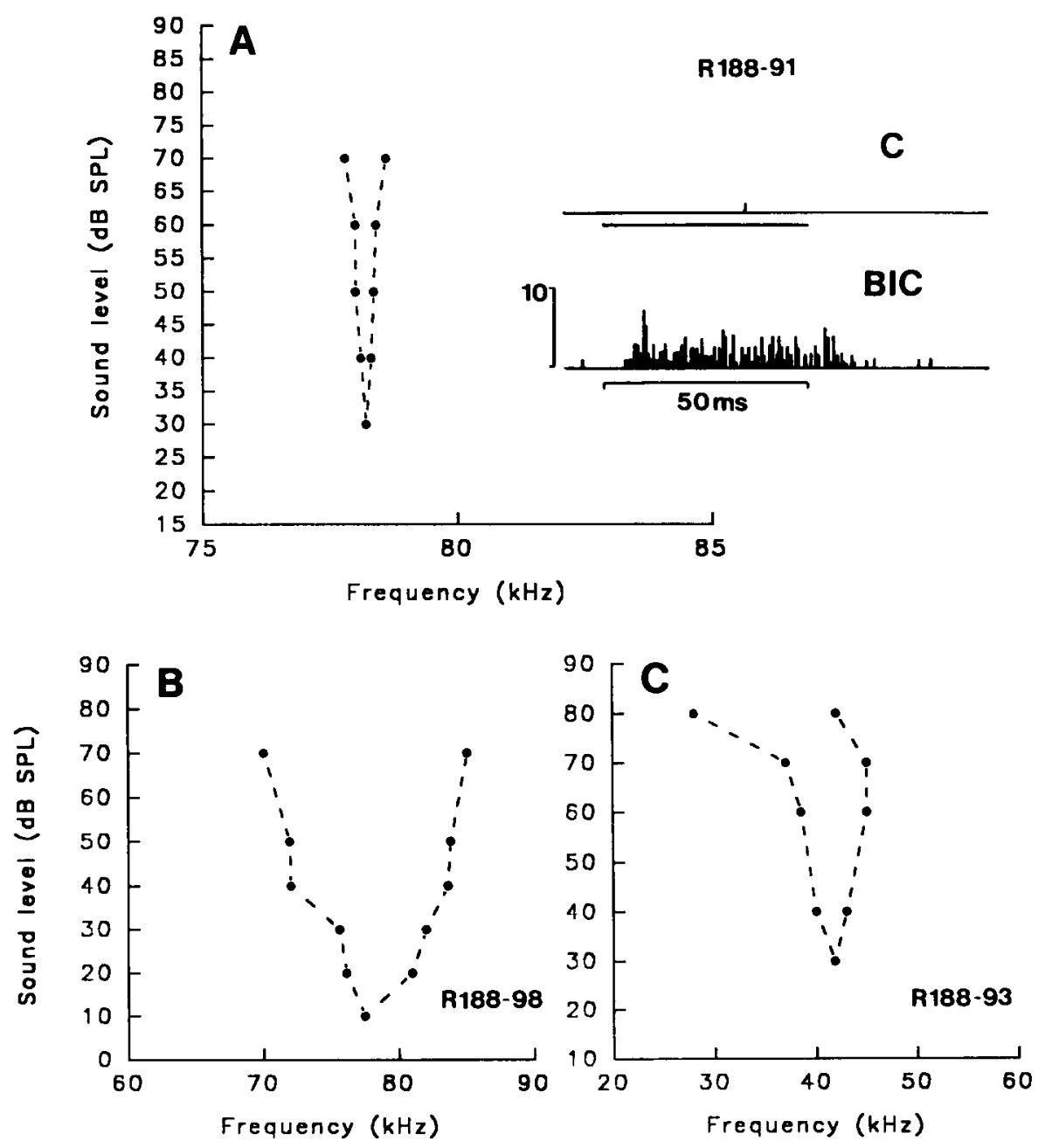

Fig. 8A-C. Excitatory tuning curves obtained under bicuculline application in different IC-neurons, which under control conditions were unresponsive to pure tone bursts. For unit R 188-91, the PST-histograms obtained for control (top) and for bicuculline (bottom) at a stimulus frequency of $78.2 \mathrm{kHz}$ ("BF") and $50 \mathrm{~dB}$ SPL are shown. Application currents for A-C: $50 \mathrm{nA}$ 


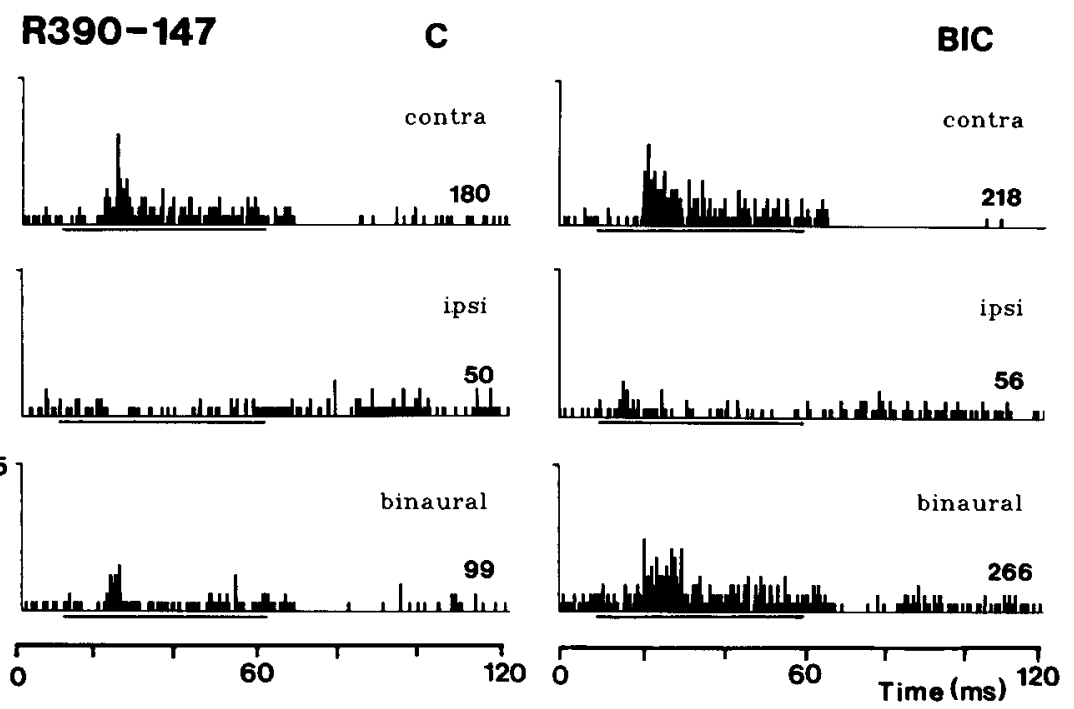

Fig. 9. Bicuculline effects on binaural response properties of a single IC-neuron (BF: $32.9 \mathrm{kHz}$ ), classified as $\mathrm{I} / \mathrm{E}$ responder under control conditions (left pannel). Bicuculline (application current $70 \mathrm{nA}$ ) abolished the inhibitory effect of stimulation of the ipsilateral ear (right pannel). Top histograms: response to stimulation of the contralateral ear (50 dB SPL); middle histograms: response to stimulation of the ipsilateral ear (60 dB SPL); lower histograms: binaural stimulation (contralateral: $50 \mathrm{~dB}$ SPL; ipsilateral: $60 \mathrm{~dB}$ SPL). Stimulus frequency corresponds to the $\mathrm{BF}$

\section{R390-184}

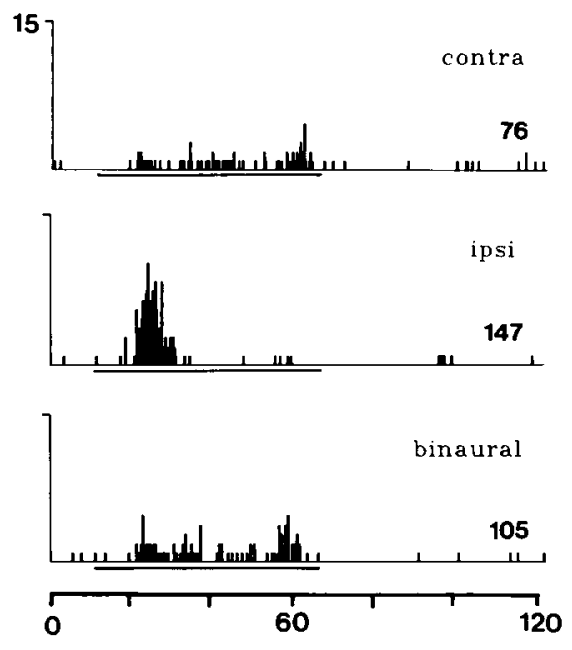

C
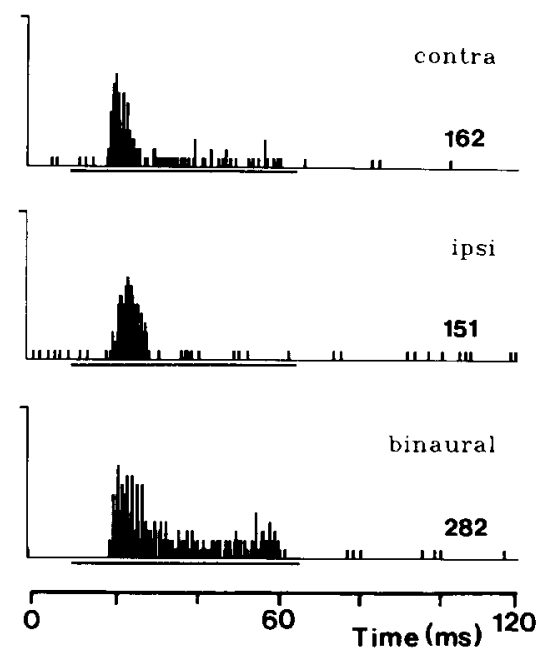

Fig. 10. Strychnine effects on binaural response properties of a single IC-neuron (BF $29.0 \mathrm{kHz}$ ) responding with excitation to monaural stimulation of the contralateral as well as the ipsilateral ear, binaural stimulation revealed a suppression of the ipsilateral response (left pannel). Strychnine application ( $80 \mathrm{nA}$; right pannel) enhanced monaural responses to contralateral stimulation and removed the inhibitory interaction during binaural stimulation. Top histograms: response to stimulation of the contralateral ear (40 dB SPL); middle histograms: response to stimulation of the ipsilateral ear (40 dB SPL); lower histograms: binaural stimulation (contralateral: $40 \mathrm{~dB}$ SPL; ipsilateral: $40 \mathrm{~dB}$ SPL). Stimulus frequency corresponds to the $\mathrm{BF}$
As already mentioned in the previous chapter, we also encountered cells which could not be driven by stimulation with pure tones under control conditions, but responded vigorously under bicuculline administration. In 8 such cells, complete excitatory tuning curves were measured during bicuculline application and representative examples are shown in Fig. 8. Most of these neurons were found in isofrequency laminae of the IC tuned to the bat's CF-component $(N=4)$ or had BFs between $63 \mathrm{kHz}$ to $71.2 \mathrm{kHz}$ which encompass the range of the frequency-modulated component of the call $(N=3)$. One of these cells was tuned to frequencies below the orientation call (BF $42.2 \mathrm{kHz}$ ).

\section{Binaural stimulation}

The effects of bicuculline application were tested under binaural stimulation in 30 IC-neurons and 19 of these cells were also tested with strychnine. Most of the binau- ral cells encountered $(N=24)$ were excited by stimulation of the contralateral ear and inhibited by stimulation of the ipsilateral ear (I/E-type). Other cells were excited by stimulation of either ipsilateral or contralateral ear $(E / E-$ response; $N=3$ ) or could only be driven during binaural stimulation (facilitatory response; $N=3$ ).

Figure 9 shows an I/E-cell, which responded tonically to monaural stimulation of the contralateral ear and with a slight decrease in spontaneous activity to monaural stimulation of the ipsilateral ear. Binaural stimulation decreased the response activity to values below the monaural contralateral response. Under bicuculline, the response to the contralateral ear was enhanced and a small excitatory response to stimulation of the ipsilateral ear was revealed with a shorter latency than the contralateral response. The response during binaural stimulation is approximately the sum of the monaural responses. Therefore, bicuculline effectively removed the binaural inhibition. This neuron was insensitive to strychnine application, as were two other I/E cells, in which bicuculline 


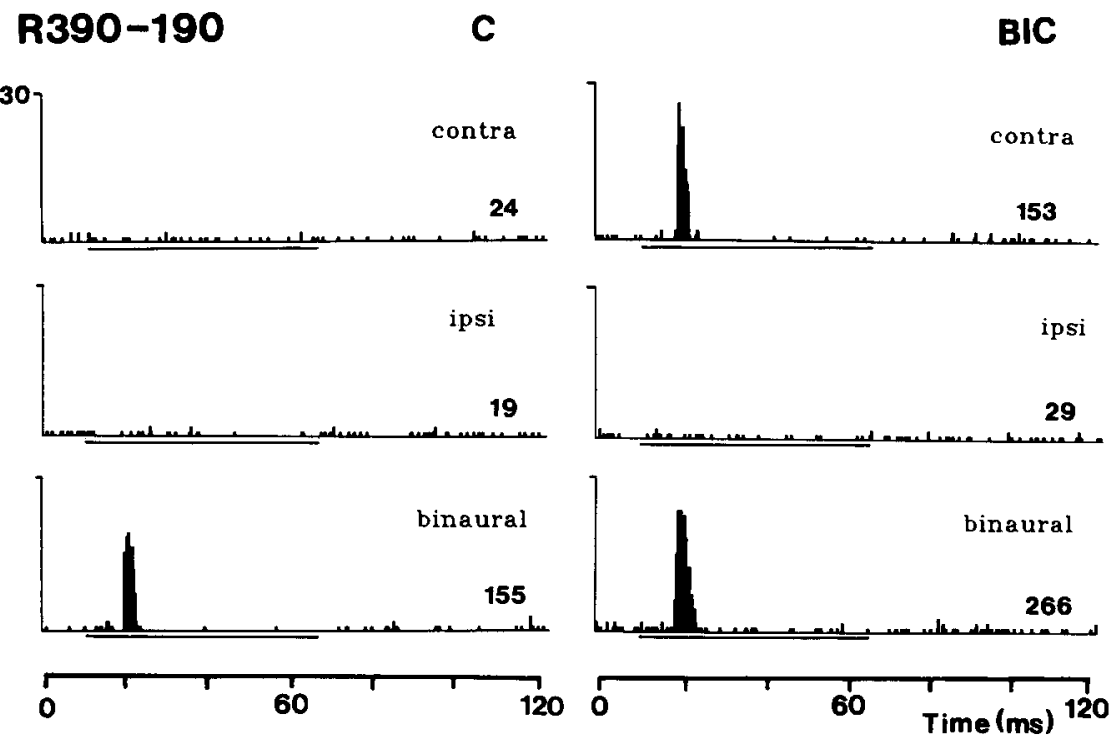
Fig. 11. Bicuculline effects on binaural re- sponse properties of a single IC-neuron, which under control conditions (left pannel) could only be driven during binaural stimu- lation $(\mathrm{BF} 61.8 \mathrm{kHz})$. Bicuculline applica- tion $(60 \mathrm{nA}$; right pannel) disinhibited the contralateral input. Top histograms: re- sponse to stimulation of the contralateral ear (40 dB SPL); middle histograms: re- sponse to stimulation of the ipsilateral ear (40 dB SPL); lower histograms: binaural stimulation (contralateral: $40 \mathrm{~dB}$ SPL; ipsilateral: $40 \mathrm{~dB}$ SPL)

removed the inhibition generated by the ipsilateral channel. In most cells, bicuculline as well as strychnine were ineffective to abolish the inhibition mediated by stimulation of the ipsilateral ear. However, the response activity during binaural stimulation was clearly higher than that obtained under control conditions since the drugs removed monaural inhibition affecting the contralateral response.

Such an effect is also clearly visible in Fig. 10 illustrating the responses of an $\mathrm{E} / \mathrm{E}$ cell firing with a build up pattern to stimulation of the contralateral ear and a phasic-burst pattern to stimulation of the ipsilateral ear. In this case, strychnine as well as bicuculline produced a brisk phasic-tonic discharge to stimulation of the contralateral ear, but the ipsilateral response was unaffected. The response to binaural stimulation is slightly higher than the contralateral response.

Figure 11 depicts the response of a cell which was only driven to correlated phasic-on activity by binaural stimulation. Under control conditions a slight decrease in spontaneous discharge rate by ipsilateral stimulation is seen. Bicuculline caused the appearance of strong phasicon discharge activity to monaural stimulation of the contralateral ear and increased spontaneous activity to stimulation of the ipsilateral ear. The response to binaural stimulation is more than the sum of monaural discharges. In two further cells with facilitatory binaural response, both bicuculline and strychnine produced similar effects.

\section{Discussion}

\section{Specificity of pharmacological effects}

The microiontophoretic technique employed in vivo is subject to several pitfalls, which have to be considered in data interpretation (Stone 1985). Current and $\mathrm{pH}$ artefacts can be confidently excluded by the present techniques, but the exact concentrations of drugs at the effector sites remain unknown and can only be indirectly if at all controlled via the injection current. The observed effects will also critically depend on the geometrical relation of the injection pipette relative to the synaptic inventory of the target cell. This point has to be kept in mind when comparing effects of a given drug in different neurons or of different drugs in the same cell.

The inhibitory effects of GABA and glycine on ICneurons were specific since they could only be antagonized by simultaneous application of the corresponding antagonists. The GABA-A-antagonist bicuculline caused drastic increases in discharge activity of each GABA-sensitive neuron. On the other hand, many glycine-sensitive IC-neurons of the horseshoe bat did not alter their response during strychnine application. This discrepancy in relative sensitivity to agonist and antagonist is hard to interprete. In our results, they might depend on the relative dosage of glycine and strychnine or be due to nonselective effects of strychnine, which is known to interact with receptors for other neurotransmitters (Faingold et al. 1989, 1991). Additionally, the acoustic paradigm used in investigations of the strychnine effects might play a critical role. For some $\mathrm{CN}$-neurons, glycine was shown to suppress tone evoked responses throughout the dynamic range, whereas strychnine only significantly increased the discharge activity at high stimulus levels (Caspary 1990). For a complex integration center such as the auditory midbrain, it might be especially critical to find the right stimulus condition for putative glycinergic inhibition to be effective. If this is the case, some aspects of the functional role of glycinergic inhibition are expected to differ from those of GABA-ergic networks.

\section{Inhibitory interactions within the IC shape temporal response patterns}

Consistent with neuropharmacological investigations in other mammals (Faingold et al. 1989, 1991), GABAergic 
networks are playing essential roles in shaping the temporal response patterns of single units in the IC of horseshoe bats. All IC-cells tested were inhibited by application of GABA. This effect can be carried by GABA-A as well as GABA-B receptors as shown by the excitatory effects of the GABA-A antagonist bicuculline and the inhibitory effects of the GABA-B-agonist baclofen (Faingold et al 1989; own unpublished data). In phasictonic cells, the time course of GABA-effects was such that the late portion of the response disappeared first, while the phasic-on component persisted longer. The GABA-A-receptor antagonist bicuculline revealed that GABA can have distinctly different effects on the temporal response patterns in the IC. It can either change the global discharge level without affecting the temporal discharge pattern or can additionally modify the temporal fine structure of responses. Global changes in discharge level of phasic and tonic IC-cells during application of antagonists could indicate that these neurons reproduce the temporal information contained in their inputs. In lower auditory brainstem centers, a similar variety of temporal discharge patterns is found as in the IC (CN: Neuweiler and Vater 1977; lateral lemniscus: Metzner and Radtke-Schuller 1987). By limiting the discharge rate, GABA determines the operating range of the cell (see also Caspary et al. 1979; Pollak and Park 1992) and thus can influence the sensitivity of the neuron and the level on which binaural inhibition operates (see below).

Bicuculline induced changes in discharge pattern show that in a subpopulation of IC-neurons, the temporal fine structure of activity is generated within the IC. This effect can be explained by the relative timing of excitatory and inhibitory inputs (see also Grothe et al. 1992) and/or by differences in rise time and strength of simultaneously arriving excitatory and inhibitory postsynaptic potentials. A change from phasic-on to tonic response activity under the influence of bicuculline suggests that the neuron receives a tonic excitatory input, whose late component is suppressed by an additional GABAergic input. The responses of other neurons show that inhibition also can act during the early phase of response activity, giving rise to build up or phasic-off patterns. A mechanism based on relative latency of inputs is conceivable for the IC of horseshoe bats, since it receives projections from several brainstem nuclei, which differ in their synaptic distance from auditory nerve (Schweizer 1981). These nuclei can be envisaged as a delay-line playing important roles in monaural (Suga 1989) as well as binaural processing (Pollak 1988).

The functional role of inhibitory interactions in creating on-discharges or improving the precision in latency of the first spike can be seen in the context of temporal analysis of sounds including measurements of pulse-echo delay (Kössl and Vater 1989; Covey et al. 1991) or restriction of the responses to low rates of periodic frequency- or amplitude-modulations (Pollak and Schuller 1981; Grothe 1990). Strychnine could produce similar effects on the temporal response pattern of single units but in a much more restricted cell population than bicuculine. Consequently, the function of shaping temporal response patterns is not the property of one particular inhibitory pathway or substance. However, at the midbrain level, GABAergic mechanisms appear to play a more prominent role in this context than glycinergic mechanisms. In the cochlear nucleus, the situation appears reversed: the temporal response patterns of single units are dominated by glycinergic interactions (Caspary 1990).

\section{Inhibitory networks shape the tuning curve in the IC}

Our results show that GABAergic circuits contribute to shaping of the tuning curve of IC-neurons. The most striking examples are units with closed tuning curves under control conditions. In these cells, bicuculline either increased the dynamic range or completely abolished upper thresholds so that normal V-shaped tuning curves resulted. Since units with closed tuning curves are commonly observed in the IC of many bat species (Molossus: Vater et al. 1979; Megaderma: Rübsamen et al. 1988; Desmodus: Schmidt et al. 1991), the functional role of this GABAergic mechanism can be seen to focus the neuronal response to low level signals such as weak echoes or environmental noise.

In many IC-cells, a broadening of the excitatory area was caused by removal of GABA-mediated inhibition. This corroborates the proposal of Suga (1964) that a sharpening of tuning curves by inhibitory mechanisms occurs in the auditory brainstem. Yang and Pollak (1992) also reported a sharpening of tuning curves in the IC of mustached bats by GABAergic inhibition but only at high levels of stimulation. In our sample, filter-qualities of neurons could be affected at high levels of stimulation only or asymmetrically at either the low or high frequency slope of the tuning curve or even close to threshold. Such differences in arrangement of - inhibitory sidebands among single IC-neurons are expected from previous studies (Möller 1978; Möller et al. 1978). In some neurons sharply tuned to the CF-component of the echolocation signal, $Q_{10 \mathrm{~dB}^{-}}$as well as $\mathrm{Q}_{40 \mathrm{~dB}^{-} \text {values were }}$ decreased by bicuculline. This could suggest that specialized filter capacities which are caused by hydromechanical specializations of the cochlea can be further sharpened by central neuronal mechanisms in the horseshoe bat. However, a general increase of $\mathrm{Q}_{10 \mathrm{~dB}}$ values in the IC as compared to lower brainstem centers has not been observed (e.g. Möller 1978). Therefore, our findings may indicate differences among IC-neurones in the degree of convergence of excitatory inputs, a feature expected to depend on the geometry of dendritic trees relative to isofrequency laminae (review Oliver and Shneiderman 1991).

In other IC-neurons, inhibitory sidebands could not be removed by bicuculline suggesting that lateral inhibition is already present in the input derived from lower brain stem sources. In fact, such inhibition is already revealed at the level of the cochlear nucleus (Neuweiler and Vater 1977; Feng and Vater 1985) and the nuclei of the lateral lemniscus (Metzner and Radtke-Schuller 1987). 
GABA-ergic mechanisms also appear to play a role in determining neuronal selectivity for signal types (Müller and Scheich 1987). Employing pure tone stimulation only, we found a significant subpopulation of cells which could not be driven by this signal type under control conditions, but responded vigorously under bicucullineapplication. We can only speculate that these cells are selective for other signal types, since FM- and noisespecialized cells have been reported in the IC of bats (e.g. Suga and Schlegel 1973). We could demonstrate that one type of such cells was only driven by binaural stimulation.

Our data further suggest that in addition to GABAergic networks, in some neurons glycinergic mechanisms can also be involved in shaping the tuning curve. Consequently, this functional role is not specific for one particular pathway.

\section{Binaural stimulation}

In agreement with previous reports, the largest population of binaural IC-cells in our limited sample responds with an I/E characteristic (Schlegel 1977a). Other response types, in particular E/E cells were rare and their response behavior under binaural stimulation was characterized by a clear inhibition of response activity. They thus differed from classical E/E-types whose binaural response is the sum of monaural inputs (e.g. Caird 1991).

In the superior olivary complex, glycinergic inhibition is responsible for binaural interaction (review: Caspary 1990). At the midbrain level, GABAergic (Faingold et al. 1989 ; present study) as well as glycinergic networks (this study) influence binaural processing.

In all IC-cells, bicuculline and/or strychnine increased the response to binaural stimulation to values well above binaural control. This effect was based on different mechanisms. In some cells, bicuculline clearly removed the inhibition caused by interactions of the contralateral excitatory input and the ipsilateral inhibitory input at the level of the IC-neuron. Such effects were also reported for bicuculline application in the IC of the rat (Faingold et al. 1989). Park and Pollak (1992) demonstrated that bicuculline could transform IC-cells with a limited receptive field into omnidirectional responders. However, in many IC-neurons of the horseshoe bat, the enhancement of binaural responses by bicuculline or strychnine was caused by removal of monaural inhibitory interactions shaping the contralateral response, i.e. the main excitatory input channel of the IC. In these cells, the inhibition caused by stimulation of the ipsilateral ear could not be antagonized (see also Faingold et al. 1991). This suggests that these neurons receive excitatory input from binaural brainstem centers, which are driven by stimulation of one ear and inhibited by stimulation of the other ear. A possible source of this input is the contralateral LSO (Casseday et al. 1988). Additionally, a convergence of a monaural inhibitory input derived from the same ear as the excitatory part of the binaural channel onto these cells, has to be postulated. This input will modify the IC-neu- ron's discharge rate/level function in response to stimulation of the excitatory ear. Such an effect is important in processing of interaural level differences and thus the coding of azimuth angle within the IC as compared to lower brainstem nuclei (review: Irvine 1986; Caird 1991). Increases in discharge activity in the excitatory channel under bicuculline application to some extent mimick response increases due to increases of sound pressure level at the excitatory ear (Schlegel 1977a). From this it can be expected, that the interaural level difference producing a certain amount of suppression will change, and the calculated azimuth position of the sound source will move towards the midline or even beyond it. Stated differently, monaural inhibition converging onto the excitatory channel of an IC-neuron, which receives binaural input from the lower brainstem could lead to a narrowing of the receptive field in the contralateral hemisphere.

\section{Possible neuronal substrates for inhibitory interactions}

There are several possible sources of inhibitory input to the IC, whose exact termination patterns in terms of segregation or convergence at particular loci have not yet been fully elucidated (reviews: Faingold et al. 1991; Oliver and Shneiderman 1991).

The substrate for GABA-mediated inhibition in the IC could include intrinsic as well as extrinsic connections. The IC contains a significant proportion of GABAimmunoreactive cells which appear to encompass subclasses of disc-shaped and stellate cells (review: Oliver and Shneiderman 1991; horseshoe bat: Vater et al. 1992b). Although direct evidence needs to be obtained, such cells could participate in local interactions within and across isofrequency laminae, thus contributing to inhibition observed at $\mathrm{BF}$ and in lateral sidebands of the tuning curves of single units. Additionally, there are several extrinsic sources of GABAergic input to the IC. In horseshoe bats, as in other mammals, the DNLL is composed of GABAergic projection neurons providing bilateral feedforward inhibition to the IC (cat: Adams and Mugnaini 1984; Shneiderman et al. 1988; horseshoe bat: Vater et al. 1990a). The intermediate nucleus and parts of the ventral nucleus of the lateral lemniscus and the LSO contain GABA-immunoreactive cell types which might include neurons projecting to the IC (Vater et al. 1992b). Furthermore, the input from the contralateral IC (Schweizer 1981) might carry inhibitory components.

Glycine-mediated inhibition is expected to be derived from extrinsic sources, since the IC of horseshoe bats lacks glycine-immunoreactive somata (Vater et al. 1990a). These inputs could arise from subpopulations of glycine-immunoreactive cells in the ventral nucleus of the lateral lemniscus, in the LSO, the dorsomedial olivary nucleus and the ventral $\mathrm{CN}$, but the identity of these neurons as projection cells to the midbrain remains to be determined. In the cat, glycinergic cells of the LSO have been shown to project to the IC (Saint Marie et al. 1989).

The following observations could indicate a partial 
segregation of GABAergic and glycinergic inputs within the ICc. Some IC-neurons were only sensitive to bicuculline, whereas others were sensitive to both antagonists. Cells exhibiting response pattern changes with bicuculline were not confined to particular IC-regions or frequency lamina, although many of them were tuned to the frequency range of the orientation call. They were found intermingled among cells, which only changed discharge level. In contrast, strychnine application led to response pattern changes in a much more restricted population of IC-cells than bicuculline and such cells were mainly found in deep regions of the ICc. It is tempting to relate these differences to the differential distributions of GABA- and glycine-immunoreactive puncta in the IC of the horseshoe bat (Vater et al. 1990a). Whereas GABAimmunoreactive puncta are abundant throughout the recording sites, glycine-immunoreactive puncta have very low density in dorsal aspects of the ICc and are most dense in its ventral parts.

Acknowledgements. We thank G. Neuweiler and P. Schlegel for critical comments on the manuscript, all members of the "bat" group for helpful discussions and $\mathrm{H}$. Hallmer for photographic work. This work was supported by SFB 204 (Gehör).

\section{References}

Adams JC, Mugnaini E (1984) Dorsal nucleus of the lateral lemniscus: A nucleus of GABAergic projection neurons. Brain Res Bull 13:585-590

Aitkin LM (1986) The auditory midbrain. Humana Press, Clifton NJ

Caird D (1991) Processing in the colliculi. In: Altschuler RA et al. (eds) Neurobiology of hearing: The central auditory system. Raven Press, New York, pp 253-292

Caspary DM (1990) Electrophysiological studies of glycinergic mechanisms in auditory brain stem structures. In: Ottersen OP, Storm-Mathiesen J (eds) Glycine neurotransmission. John Wiley \& Sons, Chichester New York Brisbane Toronto Singapore, pp 391-417

Caspary DM, Havey DC, Faingold CL (1979) Effects of microiontophoretically applied glycine and GABA on neuronal response patterns in the cochlear nuclei. Brain Res 172:179-185

Casseday JH, Covey E, Vater M (1988) Connections of the superior olivary complex in the rufous horseshoe bat Rhinolophus rouxi. J Comp Neurol 278:313-329

Covey E, Vater M, Casseday JH (1991) Binaural properties of single units in the superior olivary complex of the mustache bat. J Neurophysiol 66: 1080-1094

Faingold CL, Gehlbach G, Caspary DM (1989) On the role of GABA as an inhibitory neurotransmitter in inferior colliculus neurons: iontophoretic studies. Brain Res 500:302-312

Faingold CL, Gehlbach G, Caspary DM (1991) Functional neuropharmacology of inferior collicullus neurons. In: Altschuler RA et al. (eds) Neurobiology of hearing: The central auditory system. Raven Press, New York, pp 223-251

Feng AS, Vater M (1985) Functional organization of the cochlear nucleus of rufous horseshoe bats (Rhinolophus rouxi) : frequencies and internal connections are arranged in slabs. J Comp Neurol 235:529-553

Grothe B (1990) Versuch einer Definition des medialen Kerns des oberen Olivenkomplexes bei der Neuweltfledermaus Pteronotus parnellii. Dissertation, Ludwig Maximillian Universität, München

Grothe B, Vater M, Casseday JH, Covey E (1992) Monaural interaction of excitation and inhibiton in the medial superior olive of the mustached bat: An adaptation for biosonar. Proc Natl Acad Sci USA 89:5108-5112

Havey DC, Caspary DM (1980) A simple technique for constructing "piggy-back" multibarrel microelectrodes. Electroencephal Clin Neurophysiol 48:249-251

Irvine DRF (1986) The auditory brainstem. Progr in Sensory Physiology 7. Springer, Berlin Heidelberg New York

Kössl M, Vater M (1989) Noradrenalin enhances temporal auditory contrast and neuronal timing precision in the cochlear nucleus of the mustached bat. J Neurosci 9:4169-4178

Metzner W, Radtke-Schuller S (1987) The nuclei of the lateral lemniscus in the rufous horseshoe bat, Rhinolophus rouxi. J Comp Neurol 160:395-411

Möller J (1978) Response characteristics of inferior colliculus neurons of the awake CF-FM bat Rhinolophus ferrumequinum. II. Two-tone stimulation. J Comp Physiol 125:227-236

Möller J, Neuweiler G, Zöller H (1978) Response characteristics of inferior colliculus neurons of the awake CF-FM bat, Rhinolophus ferrumequinum. I. Single tone stimulation. J Comp Physiol 125:221-225

Moore JK, Moore RY (1987) Glutamic acid decarboxylase-like immunoreactivity in brainstem auditory nuclei of the rat. J Comp Neurol 260:157-174

Müller CM, Scheich H (1987) GABAergic inhibition increases the neuronal selectivity to natural sounds in the avian auditory forebrain. Brain Res 414:376-380

Neuweiler G (1990) Auditory adaptations for prey capture in echolocating bats. Physiol Rev 70:615-641

Neuweiler G, Vater M (1977) Response patterns to pure tones of cochlear nucleus units in the CF-FM bat, Rhinolophus ferrumequinum. J Comp Physiol 115:119-133

Oliver DL, Shneiderman A (1991) The anatomy of the inferior colliculus: A cellular basis for integration of monaural and binaural information. In: Altschuler RA et al. (eds) Neurobiology of hearing: The central auditory system. Raven Press, New York, pp 195-222

Park TJ, Pollak GD (1992) The role of GABA in shaping binaural properties and receptive fields of $E / I$ neurons in the inferior colliculus. Abstr 18th midwinter meeting of the ARO, p 237

Pollak GD (1988) Time is traded for intensity in the bat's auditory system. Hearing Res 36:107-124

Pollak GD, Casseday JH (1989) The neural basis of echolocation in bats. Springer, Berlin Heidelberg New York London Paris Tokyo

Pollak GD, Park TJ (1992) The role of GABA in shaping monaural response properties of neurons in the inferior colliculus. Abstr 18th midwintermeeting of the ARO, p 236

Pollak GD, Schuller G (1981) Tonotopic organization and encoding features of single units in inferior colliculus of horseshoe bats: Functional implications for prey identification. J Neurophysiol 45:208-226

Rübsamen R, Neuweiler G, Sripathi K (1988) Comparative collicular tonotopy in two bat species adapted to movement detection, Hipposideros speoris and Megaderma lyra. J Comp Physiol A $163: 271-285$

Saint Marie RL, Ostapoff EM, Morest DK, Wenthold RJ (1989) Glycine-immunopositive projection of the cat lateral superior olive: possible role in midbrain ear dominance. J Comp Neurol $279: 382-396$.

Schlegel P (1977a) Directional coding by binaural brainstem units of the CF-FM bat, Rhinolophus ferrumequinum. J Comp Physiol $118: 327-352$.

Schlegel P (1977b) Calibrated earphones for the echolocating bat, Rhinolophus ferrumequinum. J Comp Physiol 118:353-356

Schmidt U, Schlegel P, Schweizer H, Neuweiler G (1991) Audition in vampire bats, Desmodus rotundus. J Comp Physiol A $168: 45-51$

Schweizer H (1981) The connections of the inferior colliculus and the organization of the brainstem auditory system in the Greater horseshoe bat (Rhinolophus ferrumequinum). J Comp Neurol $270: 25-49$ 
Shneiderman A, Oliver DL, Henkel CK (1988) Connections of the dorsal nucleus of the lateral lemniscus: An inhibitory parallel pathway in the ascending auditory system? J Comp Neurol 276: $188-20$

Stone TW (1985) Microiontophoresis and pressure injection. IBRO Hdb Series: Methods in the neurosciences, Vol 8. John Wiley \& Sons, Chichester New York

Suga N (1964) Single unit activity in cochlear nucleus and inferior colliculus of echo-locating bats. J Physiol (Lond) 162: 449-474

Suga N (1969) Classification of inferior colliculus neurons of bats in terms of responses to pure tones, FM sounds and noise bursts. J Physiol (Lond) 200:555-574

Suga N (1989) Principles of auditory information-processing derived from neuroethology. J Exp Biol 146:277-286

Suga N, Schlegel P (1973) Coding and processing in the auditory systems of FM-signal-producing bats. J Acoust Soc Am 54: 174-190

Vater M, Schlegel P, Zöller H (1979) Comparative auditory neurophysiology of the inferior colliculus of two molossid bats, Molossus ater and Molossus molossus. J Comp Physiol $131: 137-145$

Vater M, Feng AS (1990) The functional organization of ascending and descending connections of the cochlear nucleus of horseshoe bats. J Comp Neurol 292:373-395

Vater M, Feng AS, Betz M (1985) An HRP-study of the frequency place map of the horseshoe bat cochlea: Morphological correlates of the sharp tuning to a narrow frequency band. J Comp Physiol A 157:671-686

Vater M, Kössl M, Horn A (1990a) Differential distribution of GABA and glycine in the ascending auditory pathway of horse- shoe bats. In: Elsner N, Roth $\mathrm{G}$ (eds) Brain-PerceptionCognition. (Proc 18th Göttingen Neurobiol Conf) G Thieme, Stuttgart New York, p 142

Vater M, Kössl M, Grothe B (1990b) Physiological effects of GABA and glycine in the inferior colliculus of horseshoe bats. In: Elsner N, Roth G (eds) Brain-Perception-Cognition. (Proc 18th Göttingen Neurobiol Conf) G Thieme, Stuttgart New York, p 143

Vater M, Kössl M, Horn AKE (1992a) Immunocytochemical aspects of the functional organization of the horseshoe bat's cochlear nucleus. In: Ainsworth WA, Evans EF, Hackney CM (eds) Cochlear nucleus: Structure and function in relation to modelling. Advances in speech, hearing and language processing. Vol. III. JAI Press Ltd, London (in press)

Vater M, Kössl M, Horn AKE (1992b) GAD- and GABAimmunoreactivity in the ascending auditory pathway of horseshoe and mustached bats. J Comp Neurol (in press)

Wenstrup JJ, Ross LS, Pollak GD (1986) Binaural response organization within a frequency band representation of the inferior colliculus: Implications for sound localization. J Neurosci $6: 962-973$

Wenthold RJ, Hunter C (1990) Immunocytochemistry of glycine and glycine receptors in the central auditory system. In: Ottersen OP, Storm-Mathiesen J (eds) Glycine neurotransmission. John Wiley \& Sons, Chichester New York Brisbane Toronto Singapore, pp 391-417

Yang LC, Pollak GD (1992) The role of GABA in sharpening tuning curves in the mustache bat's inferior colliculus. Abstr 18 th midwinter meeting of the ARO, p 190 